This item was submitted to Loughborough's Research Repository by the author.

Items in Figshare are protected by copyright, with all rights reserved, unless otherwise indicated.

\title{
How do symbolic and non-symbolic numerical magnitude processing skills relate to individual differences in children's mathematical skills? A review of evidence from brain and behavior
}

\section{PLEASE CITE THE PUBLISHED VERSION}

http://dx.doi.org/10.1016/j.tine.2013.06.001

\section{PUBLISHER}

(C) Elsevier $\mathrm{GmbH}$

\section{VERSION}

AM (Accepted Manuscript)

\section{PUBLISHER STATEMENT}

This work is made available according to the conditions of the Creative Commons Attribution-NonCommercialNoDerivatives 4.0 International (CC BY-NC-ND 4.0) licence. Full details of this licence are available at: https://creativecommons.org/licenses/by-nc-nd/4.0/

\section{LICENCE}

CC BY-NC-ND 4.0

\section{REPOSITORY RECORD}

De Smedt, Bert, Marie-Pascale Noel, Camilla K. Gilmore, and Daniel Ansari. 2019. "How Do Symbolic and Non-symbolic Numerical Magnitude Processing Skills Relate to Individual Differences in Children's Mathematical Skills? A Review of Evidence from Brain and Behavior". figshare. https://hdl.handle.net/2134/16152. 
RUNNING HEAD: Symbolic and non-symbolic number processing

How do symbolic and non-symbolic numerical magnitude processing relate to individual differences in children's mathematical skills? A review of evidence from brain and behavior

Bert De Smedt ${ }^{1}$, Marie-Pascale Noël ${ }^{2}$, Camilla Gilmore ${ }^{3}$ Daniel Ansari ${ }^{4}$

${ }^{1}$ Parenting and Special Education Research Unit, Faculty of Psychology and Educational Sciences, University of Leuven, Belgium

${ }^{2}$ Center of Cognitive Neuroscience, Institute of Psychology, Catholic University of Louvain, Belgium

${ }^{3}$ Mathematics Education Centre, Loughborough University, UK.

${ }^{4}$ Numerical Cognition Laboratory, Department of Psychology \& Brain and Mind Institute, University of Western Ontario, Canada.

Corresponding author:

Bert De Smedt, Parenting \& Special Education Research Unit, University of Leuven Leopold Vanderkelenstraat 32, box 3765, B-3000 Leuven, BELGIUM

Tel. +32 163257 05; Fax. +32 16325933

e-mail: Bert.DeSmedt@ppw.kuleuven.be 


\begin{abstract}
Many studies have tested the association between number magnitude processing and mathematics achievement. However, results appear to be quite different depending on the number format used. When using symbolic numbers (digits), data consistent and robust across studies and populations have been found, with weaker performance associated with weak math achievement and dyscalculia. However, when using non-symbolic format (dots), many conflicting findings are reported. These inconsistencies might be explained by methodological issues. Alternatively, it might be that the processes measured by non-symbolic tasks are not particularly critical for school-relevant mathematics. A few neuroimaging studies have also shown the brain signature of these effects. During numerical magnitude processing, the degree of brain activation (mostly in parietal areas) varies with the children's degree of math achievement, but the consistency of such relationships for symbolic and non-symbolic processing is unclear. These neurocognitive data provide ground for educational interventions, which seem to have positive effects on children's numerical development in typical and atypical populations.
\end{abstract}

Keywords: mathematical difficulties; magnitude representation; comparison; dyscalculia, approximate number system. 


\section{INTRODUCTION}

One important way in which cognitive neuroscience has made successful connections to educational research is by drawing attention to the importance of numerical magnitude processing as a foundation for higher-level numerical and mathematical skills (e.g., Butterworth et al., 2011; De Smedt et al., 2010). Over the last decade, this has fuelled research aimed at investigating the relationship between individual differences in numerical magnitude processing skills and arithmetic achievement in typically developing children as well as studies probing whether children with atypical mathematical development or developmental dyscalculia (DD) are impaired in their abilities to process numerical magnitudes. Such research is beginning to lay the foundations for the design and evaluation of educational interventions that foster numerical magnitude processing.

One of the outstanding questions in this emerging body of research is whether processing magnitudes in either symbolic (digits) or non-symbolic (dots) formats or both is crucial for successful mathematics achievement. Such research can pinpoint more precisely the mathematical content that should be included in specific interventions.

Beyond educational applications, establishing whether symbolic or non-symbolic numerical magnitude processing skills, or both, are predictive of children's mathematics achievement is of theoretical importance too. While non-symbolic representations of numerical magnitudes are thought be shared across species and can already be measured in early infancy (Cantlon, 2012), symbolic representations are uniquely human and relatively recent cultural inventions to provide abstract representations of numerical magnitude. Thus, by investigating the relationship between, on the one hand symbolic and non-symbolic numerical magnitude processing and, on the other, children's mathematical achievement, larger questions concerning the role of evolutionary ancient skills for the acquisition of uniquely human number skills and representations can also be constrained. In this 
contribution, we provide an integrative review of the existing body of data that has dealt with this question.

\section{DEVELOPMENT OF NON-SYMBOLIC NUMBER PROCESSING}

The nature and role of typically developing children's magnitude representations have been commonly explored with magnitude comparison tasks (Box 1). Nonsymbolic (dot) comparison tasks are frequently thought to index the precision or acuity of representations within the approximate number system (ANS), a system which allows individuals to represent and process numerical magnitude information. Representations within the ANS are noisy and become increasingly imprecise with increasing magnitude. Individuals with more precise ANS representations perform more accurately and faster on magnitude comparison tasks and they show smaller effects of ratio or distance. Typically developing children also show an increase in the precision of ANS representations over developmental time (e.g., Halberda \& Feigenson, 2008).

It has been hypothesized that performance on non-symbolic magnitude comparison tasks is related to mathematics achievement, but the evidence to support this proposal is mixed (Table 1). A number of studies have found that dot comparison performance is related to prior, concurrent and future mathematics achievement. However, many studies have failed to find such a significant relationship (see Table 1 for a summary). One possible explanation for these contrasting findings is that there is no standardized version of the dot comparison task. Studies vary in the size of the dot arrays, the way in which visual characteristics of the dots are controlled, the length of time the displays are presented and the performance measures used. This final point is particularly important as the range of possible measures includes mean accuracy, (median) RT, Weber Fraction ( $w$ ) estimates, and distance or ratio effects, which may be calculated in a number of ways on the basis of accuracy or RT. These measures capture different aspects of participants' performance, they are not interchangeable 
and may show different relationships with mathematics achievement (Mundy \& Gilmore, 2009; Price et al. 2012). However, as shown in Table 1, studies that have or have not found a significant relationship cannot be easily differentiated by factors such as the dot comparison measure employed or the range of numbers used in a straightforward manner, since both positive and negative evidence has been found for the various performance measures and there is no clear pattern to suggest that a particular performance measure of non-symbolic numerical magnitude processing is particularly sensitive in the way it relates to individual differences in mathematics achievement.

\section{SYMBOLIC PROCESSING DEVELOPMENT}

The development of symbolic number processing has been typically investigated by means of magnitude comparison tasks that involve Arabic digits (Box 1). Performance on this task improves with age (Holloway \& Ansari, 2009; Sekuler \& Mierkiewicz, 1977) and is also characterized by an effect of distance or ratio. Scores on this task are not straightforward to interpret, as they might reflect the nature of underlying ANS representations, or the mapping between symbols and the ANS representations, or alternatively the nature of symbolic representations themselves, which may or may not be linked to non-symbolic ones. Nevertheless, children's performance on these symbolic comparison tasks has been found to be robustly and significantly correlated with concurrent and future mathematics achievement 1 or 2 years later (Table 2). This relationship appears to be very consistent for overall RT on the symbolic comparison task. On the other hand, similar associations with performance measures such as accuracy and distance/ratio effects have been observed in most, but not all studies (Table 2).

ATYPICAL NUMERICAL DEVELOPMENT: DEVELOPMENTAL DYSCALCULIA

Developmental dyscalculia (DD) is a persistent and specific disorder of numerical development and mathematical learning despite normal intelligence and scholastic 
opportunities. Several authors have proposed that DD arises from a fundamental impairment in the representation of numerical magnitudes (e.g., Butterworth, 1999, 2005; Wilson \& Dehaene, 2007). This hypothesis has been tested with numerical magnitude comparison tasks (see Table 3). Data on symbolic comparison tasks has led to very consistent results showing weaker performance in DD than in controls. This difference is the most robust in terms of global RTs (e.g., De Smedt \& Gilmore, 2011; Landerl et al., 2004; Landerl \& Kölle, 2009; Rousselle \& Noël, 2007) yet group differences in the size of the distance effect (Rousselle \& Noël, 2007) and error rate (Rousselle \& Noël, 2007) have also been observed. In other words, an impairment in symbolic number processing among children with DD has been demonstrated using a variety of different dependent measures.

However, when nonsymbolic stimuli have been employed to measure numerical magnitude processing in $\mathrm{DD}$, the results have been far from conclusive. On the one hand, some studies support the hypothesis of a deficient ANS in individuals with DD and showed reduced ANS acuity (Mazzocco et al., 2011a; Piazza et al., 2010), slower and less accurate performance (Mussolin et al., 2010) or less precise estimates of dot collections (Mazzocco, et al. 2011a; Mejias et al. 2012) in DD compared to typically achieving children. On the other hand, others failed to observe any significant difference between DD and controls in nonsymbolic comparison (De Smedt \& Gilmore, 2011; Iuculano et al., 2008; Landerl \& Kölle, 2009; Rousselle \& Noël, 2007), although, in those studies, DD children displayed significant and systematic impairments in symbolic magnitude comparison. This contradictory pattern of results could partly be due to methodological differences. For instance, only Piazza et al. (2010) and Mazzocco et al. (2011a) measured the acuity of the ANS by calculating the index $w$ and found a difference between DDs and controls. The other studies used the distance or the ratio effect as an indicator of ANS precision: Some of these studies found significant differences between DD and controls (e.g., Mussolin et al., 2010; 
Price et al., 2007) whereas others did not (e.g., De Smedt \& Gilmore, 2011; Landerl \& Kölle, 2009).

Another factor that can explain this incoherent profile is the age of the children tested (see Noël \& Rousselle, 2011; Table 3). Indeed, a dissociation appears between the studies that tested younger (6 to 9-year-olds) versus older children (10-year-olds and above) with only the latter group showing significant differences for tasks using non-symbolic numbers. According to Noël and Rousselle (2011), this developmental profile suggests that the first deficit seen in DD children is specific to the magnitude processing of symbolic numbers and not to the ANS. DD children would indeed be impaired in their development of an exact representation of natural numbers (Box 2) and this would explain their difficulties in manipulating exact numbers and doing exact calculation. This, in turn, would prevent them from refining their ANS in the same way as typically developing children do and would explain why difference in number acuity between DD and control children only appears later in development. Schooling, and more specifically mathematics classes have been shown to increase the acuity of the ANS (Dehaene et al., 2008; Piazza al. in press; however see Zebian \& Ansari, 2012 for data indicating that literacy and schooling affect symbolic but not non-symbolic numerical magnitude processing). As children with DD would be slow and error prone in these mathematical activities, they would possibly benefit less from these mathematics activities on their ANS acuity, relative to their control peers. This could explain why the difference in number acuity between DD and control children only appears later in development.

\section{BRAIN IMAGING DATA}

There have been a growing number of efforts to uncover which brain regions might underlie the associations between numerical magnitude processing and mathematics achievement. In studies with both children and adults, the left and the right intraparietal sulci (IPS) have been found to be important neural correlates of numerical magnitude processing 
(see Ansari, 2008; Cohen-Kadosh et al., 2008; Dehaene et al., 2003; see Kaufmann et al., 2011 for a meta-analysis in children), with evidence suggesting that there is increasing specialization of the parietal cortex for numerical magnitude processing over developmental time (Ansari et al., 2005; Ansari \& Dhital, 2006; Cantlon et al., 2009).

Moving beyond localization, a very small set of recent studies have started to indicate that the degree to which the parietal cortex is activated during numerical magnitude processing in children is related to individual differences in their mathematics achievement. Specifically, in a functional Magnetic Resonance Imaging (fMRI) study, Bugden et al. (2012) demonstrated that the degree to which the left IPS is modulated by numerical ratio, during a symbolic number comparison task, is related to standardized measures of arithmetic fluency (over and above reading fluency) in 8-10 year old children. In other words, those children who exhibited a larger symbolic ratio effect on activity in the left IPS also displayed relatively stronger performance on the standardized tests of speeded arithmetic. In another set of recent studies (Cantlon \& Li, 2013; Emerson \& Cantlon, 2012), children viewed educational videos (Sesame Street) that had mathematical content, while their brain activity was recorded using fMRI. The degree of activity coupling (functional connectivity) between frontal and parietal brain regions during the viewing of these clips as well as how similar the brain activation of children was to that of a group of adults was found to be related to standardized measures of children's mathematics achievement. However, these studies cannot specifically constrain our understanding of the brain regions that underlie the association between symbolic and nonsymbolic numerical magnitude processing and children's mathematics achievement, since they did not explicitly address such relationships. To the best of our knowledge there does not exist a study that reveals an association between brain activation during non-symbolic number processing and individual differences in mathematical achievement in typically developing children. 
fMRI research with children with DD has revealed a largely inconclusive picture with respect to brain regions that might mediate the association between magnitude processing and DD. While some studies have shown atypical activation patterns of the parietal cortex (such as reduced distance effects on brain activation) in children with DD relative to their typically developing peers for non-symbolic (Price et al., 2007) and symbolic (Mussolin et al., 2010) numerical magnitude processing (see also Kaufmann et al., 2011 for a meta-analysis), other studies have not revealed any differences in the parietal cortex during non-symbolic number processing between children with and without DD, instead showing differences in regions related to task difficulty (Kucian et al., 2011).

Taken together, while neuroimaging methods are being used to constrain our understanding of the association between numerical magnitude processing and mathematics skills in both children with and without DD, there are currently too few studies, often with relatively small sample sizes, to allow for clear-cut conclusions to be drawn.

\section{EDUCATIONAL INTERVENTIONS}

Various attempts have been made to design educational interventions to foster the development of numerical magnitude processing. These types of interventions have been embedded in larger-scale kindergarten programs for children from low-income communities (Dyson et al., 2013; Griffin, 2004) and children at-risk for DD (Toll et al., 2013). These programs comprised a wide variety of numerical activities, including number recognition, counting, comparing sets, playing board games, etc., and have been shown to have significant effects on children's understanding of numbers and tests of early numeracy when they enter formal schooling. From these interventions, it is, however, not possible to determine the precise effects of stimulating numerical magnitude processing.

More relevant are therefore intervention studies that only focused on very specific aspects of numerical magnitude processing, as reviewed in Table 4 and Box 3. These 
interventions have been presented in game-like formats using both symbolic and nonsymbolic stimuli, and have been shown to have positive effects on children's numerical magnitude processing. It is important to note that these intervention effects have been mainly observed on symbolic but not non-symbolic measures of numerical magnitude processing (Table 3). The effects of these interventions seem to generalize to other mathematical skills, such as arithmetic (e.g., Ramani \& Siegler, 2011; Siegler \& Ramani, 2009) and standardized measures of mathematics achievement (Obersteiner et al., 2013; but see Rasanen et al., 2009 and Wilson et al., 2009), which suggests that numerical magnitude processing might be causally related to children's mathematics achievement.

Most of the existing interventions have been applied to kindergarteners or children from low-income backgrounds, yet surprisingly few studies have focused on older children or children with DD. Wilson et al. (2006) and Kucian et al. (2011) showed that computerized interventions significantly improved children with DD's numerical magnitude processing skills. Both studies did not include a control group who did not receive the intervention, which makes it difficult to evaluate whether these improvements were related to the intervention or to other factors, such as maturation or repeated testing. Interestingly, data by Vilette et al. (2010) indicate that in children with DD a short computerized game that focuses on the numerical meaning of symbolic numbers leads to larger improvements in (symbolic) number processing and calculation than a game that only taps into exact calculation, without specific attention to the numerical meaning of symbolic numbers. In all, it will be crucial for future research to investigate whether the interventions reviewed above also improve the numerical skills of children with DD.

A next step will be to investigate how brain activity changes in response to the educational interventions reviewed above, an approach that has been successfully applied in the field of reading (McCandliss, 2010). Only one study has examined the effect of a 
computerized numerical training program "Rescue Calcularis" on brain activity in children with and without DD (Kucian et al., 2011) and revealed significant neuroplastic changes of the intervention in both groups. Future research is, however, needed to pinpoint more carefully how these interventions affect brain activity in children.

\section{SUMMARY AND CONCLUSIONS}

One of the most robust findings in the literature that sought to uncover the association between numerical magnitude processing and mathematics achievement is that children who are better in determining which of two symbolic numbers is the largest have higher achievement in mathematics. Relatedly, children with DD show significant deficits in their ability to compare symbolic numbers. These data may suggest that children with low mathematics achievement or DD have difficulties in mapping symbols to their ANS representation or, alternatively, that they fail to adequately construct a system for the representation of symbolic number that is fundamentally different from the ANS (see Box 2).

Data on non-symbolic comparison tasks, however, have been inconclusive so far, in both typically developing and DD populations. These inconsistencies might be explained by differences in the age of the participants, the stimuli used as well as indices that were calculated to tap into nonsymbolic processing and mathematics achievement. While there may well be important methodological issues that obscure the relationship between non-symbolic magnitude processing and mathematics achievement in many of the studies we have reviewed, it is nevertheless important to note that the correlations between symbolic numerical magnitude processing and mathematics achievement do not appear to be subject to such constraints. In view of this, it can be argued that such relationships are more robust and that the difficulty in finding relationships between non-symbolic numerical magnitude processing and mathematics achievement may indicate that the kinds of representations and 
processes measured by these tasks are not particularly critical for children's development of school-relevant mathematical competencies.

It is important to point out that the existing body of studies have typically employed standardized or curriculum measures of mathematics achievement, which encompass a range of mathematical skills (e.g. number fact knowledge, conceptual understanding, strategy use and proficiency). It is likely that any meaningful relationship between numerical magnitude representations and mathematics will vary across different mathematical skills. In other words, numerical magnitude processing will be more important for some aspects of mathematical competencies than others. Thus, more specific measures of mathematical performance will be needed to explore such specific associations (e.g., Vanbinst et al., 2013). Relatively few longitudinal studies have been conducted to investigate how the associations between numerical magnitude processing and mathematics achievement change with age. Such research is, however, necessary to unravel the developmental trajectory of these associations. These data will also help to reveal developmental changes in impairments in numerical magnitude processing, i.e. the precise time course as to when deficits in symbolic and/or non-symbolic processing emerge.

Intervention research indicates that board games and computer games can be used to effectively foster children's symbolic representations of magnitude. These games seem to have effects on more general measures of mathematics achievement, although not all studies have observed such generalization effects and not all studies have used matched control groups to evaluate the specificity of any training effects observed. It should be noted that the studies reviewed above have typically included both symbolic and non-symbolic interventions. Future studies should contrast interventions that focus on non-symbolic processing, symbolic processing or both, to evaluate which of these interventions has the largest impact on children's numerical magnitude processing and more generally on their 
mathematical development. This type of research is also necessary to determine whether children's symbolic and/or nonsymbolic processing skills are causally related to their mathematics achievement. In view of the above- reviewed studies, it would even be more compelling to run these studies across different ages, to verify which type of intervention is appropriate at which age.

From a practical point of view, the existence of computer games to foster children's understanding of numerical magnitudes is extremely relevant for the early intervention of atrisk children. Such games allow teachers and parents not only to stimulate this knowledge but also provide a motivating environment. This is particularly interesting in view of the increasing availability of tablets and smartphones, which offer opportunities to practice these skills at home. 


\section{REFERENCES}

Anderson, U. \& Ostergren, R. (2012). Number magnitude processing and basic cognitive functions in children with mathematical learning disabilities. Learning and Individual Differences, 22, 701-714.

Ansari, D. (2008). Effects of development and enculturation on number representation in the brain. Nature Reviews Neuroscience, 9, 278-291.

Ansari, D., \& Dhital, B. (2006). Age-related changes in the activation of the intraparietal sulcus during nonsymbolic magnitude processing: An event-related functional magnetic resonance imaging study. Journal of Cognitive Neuroscience, 18, 18201828.

Ansari, D., Garcia, N., Lucas, E., Hamon, K., \& Dhital, B. (2005). Neural correlates of symbolic number processing in children and adults. Neuroreport, 16, 1769-1773.

Bonny, J. W., \& Lourenco, S. F. (2013). The approximate number system and its relation to early math achievement: Evidence from the preschool years. Journal of Experimental Child Psychology, 114, 375-388.

Bugden, S., \& Ansari, D. (2011). Individual differences in children's mathematical competence are related to the intentional but not automatic processing of Arabic numerals. Cognition, 118, 32-44.

Bugden, S., Price, G. R., McLean, D. A. \& Ansari, D. (2012) The role of the left intraparietal sulcus in the relationship between symbolic number processing and children's arithmetic competence. Developmental Cognitive Neuroscience, 2, 448-457.

Butterworth, B. (1999). The Mathematical Brain. London: Macmillan.

Butterworth, B. (2005). Developmental dyscalculia. In J. I. D. Campbell (Ed.), Handbook of Mathematical Cognition (pp. 455-467). New York: Psychology Press. 
Butterworth, B., Varma, S., \& Laurillard, D. (2011). Dyscalculia: from brain to education. Science, 332, 1049-1053.

Cantlon, J. F., Libertus, M. E., Pinel, P., Dehaene, S., Brannon, E. M., \& Pelphrey, K. A. (2009). The neural development of an abstract concept of number. Journal of Cognitive Neuroscience, 21, 2217-2229.

Cantlon, J. F. \& Li, R. (2013) Neural activity during natural viewing of Sesame Street statistically predicts test scores in early childhood. PLOS Biology, 11: e1001462.

Cantlon, J. F. (2012) Math, monkeys and the developing brain. Proceedings of the National Academy of Sciences USA, 109, 10725-32.

Carey, S. (2004). Bootstrapping and the origin of concepts. Daedalus, 133, 59-68.

Carey, S. (2009). The origin of concepts. Oxford: Oxford University Press.

Castronovo, J., \& Göbel, S. M. (2012). Impact of high mathematics education on the number sense. PLoS ONE, 7(4), e33832.

Cohen-Kadosh, R., Lammertyn, J., \& Izard, V. (2008). Are numbers special? An overview of chronometric, neuroimaging, developmental and comparative studies of magnitude representation. Progress in Neurobiology, 84, 132-147.

De Smedt, B., \& Gilmore, C. K. (2011). Defective number module or impaired access? Numerical magnitude processing in first graders with mathematical difficulties. Journal of Experimental Child Psychology, 108, 278-292.

De Smedt, B., Ansari, D., Grabner, R. H., Hannula, M. M., Schneider, M., \& Verschaffel, L. (2010). Cognitive neuroscience meets mathematics education. Educational Research Review, 5, 97-105.

De Smedt, B., Verschaffel, L., \& Ghesquière, P. (2009). The predictive value of numerical magnitude comparison for individual differences in mathematics achievement. Journal of Experimental Child Psychology, 103, 469-479. 
Dehaene, S., Piazza, M., Pinel, P., \& Cohen, L. (2003). Three parietal circuits for number processing. Cognitive Neuropsychology, 20, 487-506.

Dehaene, S., Izard, V., Spelke, E., et al. (2008). Log or linear? Distinct intuitions of the number scale in Western and Amazonian indigene cultures. Science, 320, 1217-1220.

Desoete, A., Ceulemans, A., De Weerdt, F., \& Pieters, S. (2012). Can we predict mathematical learning disabilities from symbolic and non-symbolic comparison tasks in kindergarten? Findings from a longitudinal study. British Journal of Educational Psychology, 82, 64-81.

Durand, M., Hulme, C., Larkin, R., \& Snowling, M. (2005). The cognitive foundations of reading and arithmetic skills in 7- to 10-year-olds. Journal of Experimental Child Psychology, 91, 113-136.

Dyson, N. I., Jordan, N. C., \& Glutting, J. (2013). A number sense intervention for lowincome kindergartners at risk for mathematical difficulties. Journal of Learning Disabilities, 46, 166-181.

Emerson, R. W. \& Cantlon, J. F. (2012) Early math achievement and functional connectivity in the fronto-parietal network. Developmental Cognitive Neuroscience, 15, S139S151.

Ferreira, F. O., Wood, G., Pinheiro-Chagas, P., Lonnemann, J., Krinzinger, H., Willmes, K., \& Haase, V. G. (2012). Explaining school mathematics performance from symbolic and nonsymbolic magnitude processing: similarities and differences between typical and low-achieving children. Psychology \& Neuroscience, 5, 37-46 .

Fuhs, M. W., \& McNeil, N. M. (2013). ANS acuity and mathematics ability in preschoolers from low-income homes: contributions of inhibitory control. Developmental Science, $16,136-148$. 
Gebuis, T., \& Reynvoet, B. (2012). The interplay between nonsymbolic number and its continuous visual properties. Journal of Experimental Psychology: General, 141, 642648.

Griffin, S. (2004). Building number sense with Number Worlds: a mathematics program for young children. Early Childhood Research Quarterly, 19, 173-180.

Halberda, J., \& Feigenson, L. (2008). Developmental change in the acuity of the "number sense": The approximate number system in 3-, 4-, 5-, and 6-year-olds and adults. Developmental Psychology, 44, 1457-1465.

Halberda, J., Ly, R., Wilmer, J. B., Naiman, D. Q., \& Germine, L. (2012). Number sense across the lifespan as revealed by a massive Internet-based sample. Proceedings of the National Academy of Sciences, 109, 11116-1120.

Halberda, J., Mazzocco, M. M. M., \& Feigenson, L. (2008). Individual differences in nonverbal number acuity correlate with maths achievement. Nature, 455(7213), 665-668.

Holloway, I. D., \& Ansari, D. (2009). Mapping numerical magnitudes onto symbols: The numerical distance effect and individual differences in children's mathematics achievement. Journal of Experimental Child Psychology, 103, 17-29.

Inglis, M., Attridge, N., Batchelor, S., \& Gilmore, C. (2011). Non-verbal number acuity correlates with symbolic mathematics achievement: But only in children. Psychonomic Bulletin \& Review, 18, 1222-1229.

Iuculano, T., Tang, J., Hall, C. W. B., \& Butterworth, B. (2008). Core information processing deficits in developmental dyscalculia and low numeracy. Developmental Science, 11, 669-680.

Kaufmann, L., Wood, G., Rubinsten, O., \& Henik, A. (2011). Meta-analyses of developmental fMRI studies investigating typical and atypical trajectories of number processing and calculation. Developmental Neuropsychology, 36, 763-787. 
Kolkman, M. E., Kroesbergen, E. H., \& Leseman, P. P. M. (2013). Early numerical development and the role of non-symbolic and symbolic skills. Learning and Instruction, 25, 95-103.

Kucian, K., Loenneker, T., Martin, E. \& von Aster, M. (2011) Non-symbolic distance effect in children with and without developmental dyscalculia: a parametric fMRI study. Developmental Neuropsychology, 36, 741-62.

Landerl, K., \& Kölle, C. (2009). Typical and atypical development of basic numerical skills in elementary school. Journal of Experimental Child Psychology, 103, 546-565.

Landerl, K., Bevan, A., \& Butterworth, B. (2004). Developmental dyscalculia and basic numerical capacities: A study of 8-9-year-old students. Cognition, 93, 99-125.

Landerl, K., Fussenegger, B., Moll, K. \& Willburger, E. (2009). Dyslexia and dyscalculia: Two learning disorders with different cognitive profiles. Journal of Experimental Child Psychology, 103, 309-324.

Libertus, M. E., Feigenson, L., \& Halberda, J. (2011). Preschool acuity of the approximate number system correlates with school math ability. Developmental Science, 14, $1292-$ 1300.

Libertus, M. E., Feigenson, L., \& Halberda, J. (in press). Is approximate number precision a stable predictor of math ability? Learning and Individual Differences. doi:10.1016/j.lindif.2013.02.001

Libertus, M. E., Odic, D., \& Halberda, J. (2012). Intuitive sense of number correlates with math scores on college-entrance examination. Acta Psychologica, 141, 373-379.

Lonnemann, J., Linkersdörfer, J., Hasselhorn, M., \& Lindberg, S. (2011). Symbolic and nonsymbolic distance effects in children and their connection with arithmetic skills. Journal of Neurolinguistics, 24, 583-591. 
Lourenco, S. F., Bonny, J. W., Fernandez, E. P., \& Rao, S. (2012). Nonsymbolic number and cumulative area representations contribute shared and unique variance to symbolic math competence. Proceedings of the National Academy of Sciences, 109, 1873718742.

Lyons, I. M., \& Beilock, S. L. (2011). Numerical ordering ability mediates the relation between number sense and arithmetic competence. Cognition, 121, 256-261.

Lyons, I.M., Ansari, D. \& Beilock, S.L. (2012) Symbolic estrangement: evidence against a strong association between numerical symbols and the quantities they represent. Journal of Experimental Psychology: General, 141, 635-641.

Mazzocco, M. M. M., Feigenson, L. \& Halberda, J. (2011a). Impaired acuity of the approximate number system underlies mathematical learning disability (dyscalculia). Child Development, 82, 1224-1237.

Mazzocco, M. M. M., Feigenson, L., \& Halberda, J. (2011b). Preschoolers' precision of the approximate number system predicts later school mathematics performance. $P L o S$ ONE, 6(9).

McCandliss, B. D. (2010). Educational neuroscience: The early years. Proceedings of the National Academy of Sciences of the United States of America, 107, 8049-8050.

Mejias, S., Mussolin, C., Rousselle, L., Grégoire, J. \& Noël, M-P. (2012). Numerical and nonnumerical estimation in children with and without mathematical learning disabilities. Child Neuropsychology, 18, 550-575.

Mundy, E., \& Gilmore, C. K. (2009). Children's mapping between symbolic and nonsymbolic representations of number. Journal of Experimental Child Psychology, 103, 490-502.

Mussolin, C., De Volder, A., Grandin, C., Schloegel, X., Nassongne, M.C., \& Noel, M.-P. (2010). Neural correlates of symbolic number comparisons in developmental dyscalculia. Journal of Cognitive Neuroscience, 22, 860-874. 
Mussolin, C., Mejias, S. \& Noël, M-P. (2010). Symbolic and non-symbolic number comparison in children with and without dyscalculia. Cognition, 115, 10-25.

Noël, M-P. \& Rousselle, L. (2011). Developmental changes in the profiles of dyscalculia: an explanation based on a double exact-and-approximate number representation model. Frontiers in Human Neuroscience, 5, 165. doi: 10.3389/fnhum.2011.00165.

Noël, M-P., Grégoire, J., Meert, G. \& Seron, X. (2008). The innate schema of natural numbers does not explain historical, cultural, and developmental differences. Behavioral and Brain Sciences, 31, 6, 664-665.

Obersteiner, A., Reiss, K., \& Ufer, S. (2013). How training on exact or approximate mental representations of number can enhance first-grade students' basic number processing and arithmetic skills. Learning and Instruction, 23, 125-135.

Piazza, M., Facoetti, A., Trussardi, A. N., Berteletti, I., Conte, S., Lucangeli, D., Dehaene, S. \& Zorzi, M. (2010). Developmental trajectory of number acuity reveals a severe impairment in developmental dyscalculia. Cognition, 116, 33-41.

Piazza, M., Pica, P., Izard, V., Spelke, E., dehaene, S. (in press). Education enhances the acuity of the non-verbal approximate number system. Psychological Science.

Price, G. R., Holloway, I., Rasanen, P., Vesterinen, M., \& Ansari, D. (2007). Impaired parietal magnitude processing in developmental dyscalculia. Current Biology, 17, R1042-R1043.

Price, G. R., Palmer, D., Battista, C., \& Ansari, D. (2012). Nonsymbolic numerical magnitude comparison: Reliability and validity of different task variants and outcome measures, and their relationship to arithmetic achievement in adults. Acta Psychologica, 140, 5057. 
Ramani G. B. \& Siegler R. S. (2011) Reducing the gap in numerical knowledge between lowand middle-income preschoolers. Journal of Applied Developmental Psychology, 32, 146-159.

Ramani, G. B., \& Siegler, R. S. (2008). Promoting broad and stable improvements in lowincome children's numerical knowledge through playing number board games. Child Development, 79, 375-394.

Rasanen, P., Salminen, J., Wilson, A. J., Aunio, P., \& Dehaene, S. (2009). Computer-assisted intervention for children with low numeracy skills. Cognitive Development, 24, 450472.

Rousselle, L. \& Noël, M-P. (2007). Basic numerical skills in children with mathematics learning disabilities: A comparison of symbolic versus non-symbolic number magnitude processing. Cognition, 102, 361-395.

Sasanguie, D., Göbel, S. M., Moll, K., Smets, K., \& Reynvoet, B. (2013). Approximate number sense, symbolic number processing, or number-space mappings: What underlies mathematics achievement? Journal of Experimental Child Psychology, 114, $418-431$.

Sasanguie, D., Van den Bussche, E., \& Reynvoet, B. (2012a). Predictors for mathematics achievement? Evidence from a longitudinal study. Mind, Brain, and Education, 6, $119-128$.

Sasanguie, D., De Smedt, B., Defever, E., \& Reynvoet, B. (2012b). Association between basic numerical abilities and mathematics achievement. British Journal of Developmental Psychology, 30, 344-357.

Sekuler, R., \& Mierkiewicz, D. (1977). Children's judgments of numerical inequality. Child Development, 48, 630-633. 
Siegler R. S. \& Ramani G. B. (2009) Playing linear number board games - but not circular ones - improves low-income preschoolers' numerical understanding. Journal of Educational Psychology, 101, 545-560.

Siegler, R. S. (2009). Improving the numerical understanding of children from low-income families. Child Development Perspectives, 3, 118-124.

Soltesz, F., Szücs, D., \& Szücs, L (2010). Relationships among magnitude representation, counting, and memory in 4- to 7-year-old children: a developmental study. Behavioral and Brain Functions, 6, 13. doi:10.1186/1744-9081-6-13

Toll, S., \& van Luit, J. E. H. (2013). Accelerating the early numeracy development of kindergartners with limited working memory skills through remedial education. Research in Developmental Disabilities, 34, 745-755.

Vanbinst, K., Ghesquière, P., \& De Smedt, B. (2012). Numerical Magnitude Representations and Individual Differences in Children's Arithmetic Strategy Use. Mind, Brain, and Education, 6, 129-136.

Vilette, B., Mawart, C., Rusinek, S. (2010). L'outil “estimator”, la ligne numérique mentale et les habiletés arithmétiques. Pratiques Psychologiques, 16, 203-214.

Whyte, J. C., \& Bull, R. (2008). Number games, magnitude representation, and basic number skills in preschoolers. Developmental Psychology, 44, 588-596.

Wiese, H. (2003). Numbers, language and the human mind. Cambridge: Cambridge University Press.

Wiese, H. (2007). The co-evolution of number concepts and counting words. Lingua, 117, $758-772$.

Wilson A. J., Dehaene S., Dubois O. \& Fayol M. (2009) Effects of an adaptive game intervention on accessing number sense in low-socioeconomic-status kindergarten children. Mind, Brain, and Education, 3, 224-234. 
Wilson, A. J., \& Dehaene, S. (2007). Number sense and developmental dyscalculia. . In D. Coch, G. Dawson \& K. Fischer (Eds.), Human behavior, learning, and the developing brain: Atypical development (2nd ed.) (pp. 212-237). New York: Guilford Press.

Wilson, A. J., Revkin, S. K., Cohen, D., Cohen, L., \& Dehaene, S. (2006). An open trial assessment of "The Number Race", an adaptive computer game for remediation of dyscalculia. Behavioral and Brain Functions, 2, 20.

Zebian, S \& Ansari, D. (2012) Differences between literates and illiterates on symbolic but not nonsymbolic numerical magnitude processing. Psychonomic Bulletin \& Review, 19, 93-100. 


\section{ACKNOWLEDGEMENTS}

Bert De Smedt is funded by grant GOA 2012/010 of the Research Fund KULeuven, Belgium. Marie-Pascale Noël is supported by the National Research Fund of Belgium. Camilla Gilmore is funded by a British Academy Fellowship. Daniel Ansari is funded by the Natural Sciences and Engineering Council of Canada (NSERC), the Canadian Institutes of Health Research (CIHR) and the Canada Research Chairs Program (CRC). 


\section{TABLES}

Table 1

The nature of the relationship between nonsymbolic (dot) comparison task performance and mathematics achievement in typically developing participants. The dot comparison measure(s) used and number range of the task are given in brackets.

Relationship between dot comparison performance and mathematics

\begin{tabular}{|c|c|}
\hline Significant & Nonsignificant \\
\hline Children & Children \\
\hline Halberda et al. (2008) $[w ; 5-16]^{\mathrm{a}}$ & Holloway \& Ansari (2009) [NDE; 1-9] \\
\hline Mundy \& Gilmore (2009) [acc; 1-9] & Mundy \& Gilmore (2009) [NDE; 1-9] \\
\hline Inglis et al. (2011) [w; 5-22] & Soltesz et al. (2010) [acc, RT, NRE; 4-20] \\
\hline Libertus et al. (2011) [acc, $w, \mathrm{RT} ; 4-15]$ & Lonneman et al. (2011) [NDE; 4-6] \\
\hline Mazzocco et al. (2011b) [acc, $w ; 1-14]^{\mathrm{a}}$ & Ferreira et al. (2012) [acc; 20-44] \\
\hline Bonny \& Lourenco (2013) [w, acc; 4-12] & Sasanguie et al. (2012a) [RT/error, NDE; 1-9] \\
\hline \multirow[t]{5}{*}{ Libertus et al. (2013) [acc, $w, \mathrm{RT} ; 4-15]$} & Sasanguie et al. (2012b) [RT/error, NDE; 1-9] ${ }^{\mathrm{a}}$ \\
\hline & Vanbinst et al. (2012) [NDE; 1-9] \\
\hline & Fuhs \& McNeil (2013) [acc; 1-30] \\
\hline & Kolkman et al. (2013) [acc; 1-100] \\
\hline & Sasanguie et al. (2013) [w, acc; 6-26 $]^{\mathrm{a}}$ \\
\hline Adults & Adults \\
\hline Lyons \& Beilock (2011) [w; 1-9] & Inglis et al. (2011) [w;9-70] \\
\hline Halberda et al. (2012) [w, RT; 5-20] & Castronovo \& Göbel (2012) [w; 12-40] \\
\hline Libertus et al .(2012) $[w ; 5-20]$ & Price et al. (2012) [w, NDE; 6-40] \\
\hline Lourenco et al. (2012) [acc; 5-14] & \\
\hline
\end{tabular}


$\mathrm{Acc}=$ accuracy $; \mathrm{NDE}=$ numerical distance effect; $\mathrm{NRE}=$ numerical ratio effect $; \mathrm{RT}=$ response time; $w=$ estimates of Weber fraction; ${ }^{\mathrm{a}}$ Longitudinal data. 


\section{Table 2}

The nature of the relationship between symbolic (digit) comparison task performance and mathematics achievement in typically developing participants. The digit comparison measure(s) used and number range of the task are given in brackets.

\begin{tabular}{c|c}
\hline \multicolumn{2}{c}{ Relationship between digit comparison performance and mathematics } \\
\hline Significant & Nonsignificant \\
\hline Children & Children \\
Durand et al. (2005) [acc; 3-9] & Lonneman et al. (2011) [NDE; 1-3] \\
De Smedt et al. (2009) [acc, RT, NDE, 1-9] & Ferreira et al. (2012) [acc ; 1-9] \\
Holloway \& Ansari (2009) [RT, NDE; 1-9] & Sasanguie et al. (2012b) [NDE; 1-9] ${ }^{\text {a }}$ \\
Mundy \& Gilmore (2009) [acc, NDE; 1-9] & Sasanguie et al. (2013) [NDE; 1-9] ${ }^{\text {a }}$ \\
Bugden \& Ansari (2011) [RT, NDE; 1-9] & \\
Lonneman et al. (2011) [RT, NDE; 4-6] & \\
Sasanguie et al. (2012a) [RT/error, NDE; 1-9] & \\
Sasanguie et al. (2012b) [RT/error; 1-9] ${ }^{\text {a }}$ & \\
Adults & \\
Vanbinst et al. (2012) [NDE; 1-9] & \\
Kolkman et al. (2013) [acc; 1-100] & \\
Sasanguie et al. (2013) [RT; 1-9] ${ }^{\text {a }}$ & \\
\hline Adronovo \& Göbel (2012) [RT, NDE; 31- & \\
\hline
\end{tabular}

Acc $=$ overall accuracy; $\mathrm{RT}=$ overall response time; $\mathrm{NDE}=$ numerical distance/ratio effect. ${ }^{\text {a }}$ Longitudinal data. 
Table 3

Comparison of the performance of children with developmental dyscalculia (DD) and matched controls (C) in symbolic or non-symbolic number comparison tasks.

\begin{tabular}{|c|c|c|c|c|c|}
\hline \multirow[t]{2}{*}{$\overline{\text { Study }}$} & Age & Symbolic & Symbolic & Non-symbolic & Non-symbolic \\
\hline & (years) & significant & $\mathrm{ns}$ & significant & ns \\
\hline
\end{tabular}

De Smedt \& Gilmore

6

RT: [1-9]

NDE(RT)

RT, NDE(RT): [1-9]

(2011)

Rousselle \& Noël

$7 \quad$ RT, Size(RT), NDE(RT), Acc: [1-9]

RT, NDE(RT), Acc:

(2007)

Landerl \& al. (2004)

8-9

RT : [1-9]

NDE(RT)

Iuculano \& al. (2008)

8-9

RT: [1-9]

[5-28]

\begin{tabular}{|c|c|c|c|c|}
\hline & & & & RT, Acc: [1-9] \\
\hline & & & & RT: [10-58] \\
\hline Landerl \& Kölle (2009) & $8-10$ & RT: [1-9] & NDE(RT) & RT, NDE(RT): [20-72] \\
\hline
\end{tabular}


Landerl, Fussenegger \& $\quad 8-10$

al. (2009)

Piazza \& al. (2010)

Mussolin \& al. (2010)

Price \& al. (2007)

12

Anderson \& al., (2012)

$11-13$

RT, NDE(RT): [1-9]

RT:[2-digit]
RT: [20-72]

$W:[12-40]$

RTs

Acc, RT

NDE(Acc): [1-9]

Acc, RT
Acc, NDE(acc), RT

RT: [2-8]

Mazzocco \& al. (2011a) 14

$w:[5-16]$

Acc $=$ overall accuracy $; \mathrm{RT}=$ overall response time; $\mathrm{NDE}=$ numerical distance $/$ ratio effect 
Table 4

Cognitive interventions that focused on numerical magnitude processing

\begin{tabular}{|c|c|c|c|c|c|c|c|c|}
\hline Study & $\begin{array}{l}\text { Sample } \\
\text { size }\end{array}$ & Age (years) & $\begin{array}{l}\text { Participant } \\
\text { group(s) }\end{array}$ & Intervention & Control & Duration & Outcome(s) & Main Effect(s) \\
\hline Whyte \& Bull (2008) & 54 & 3.8 & $\begin{array}{l}\text { Middle-class and } \\
\text { working class }\end{array}$ & $\begin{array}{c}\text { Linear number BG } \\
\text { Nonlinear number BG }\end{array}$ & Linear color BG & $6 \times 25 \min$ & Symbolic comparison & Number BG > Color BG \\
\hline $\begin{array}{l}\text { Ramani \& Siegler } \\
(2008)\end{array}$ & 124 & 4.9 & Low-income & Number BG & Color BG & $4 \times 15-20 \mathrm{~min}$ & Symbolic comparison & $\begin{array}{c}\text { Number } \mathrm{BG}>\text { Color } \mathrm{BG} \\
\text { Effect remained after } 9 \\
\text { weeks }\end{array}$ \\
\hline $\begin{array}{l}\text { Siegler \& Ramani } \\
(2009)\end{array}$ & 88 & 4.8 & Low-income & Linear number BG & $\begin{array}{l}\text { Circular number BG } \\
\text { Numerical activities } \\
\text { control }\end{array}$ & $5 \times 15-20 \min$ & $\begin{array}{c}\text { Symbolic comparison } \\
\text { Arithmetic }\end{array}$ & $\begin{array}{c}\text { Linear BG }>\text { Circular }+ \\
\text { numerical control }\end{array}$ \\
\hline $\begin{array}{l}\text { Ramani \& Siegler } \\
(2011)\end{array}$ & 88 & 4.0 & $\begin{array}{l}\text { Middle-upper } \\
\text { class }\end{array}$ & Linear number BG & $\begin{array}{c}\text { Circular number BG } \\
\text { Numerical activities } \\
\text { control }\end{array}$ & $5 \times 15-20 \mathrm{~min}$ & $\begin{array}{c}\text { Symbolic comparison } \\
\text { Arithmetic }\end{array}$ & $\begin{array}{c}\text { Linear BG }>\text { Circular }+ \\
\text { numerical control } \\
\text { Linear BG showed } \\
\text { transfer to arithmetic }\end{array}$ \\
\hline Wilson et al. 2006 & 9 & 8.1 & DD & NRG & None & $16 \times 20-30 \mathrm{~min}$ & $\begin{array}{c}\text { Symbolic comparison } \\
\text { Nonsymbolic } \\
\text { comparison } \\
\text { Addition } \\
\text { Subtraction }\end{array}$ & $\begin{array}{l}\text { Performance increased } \\
\text { only in symbolic } \\
\text { comparison and } \\
\text { subtraction }\end{array}$ \\
\hline Wilson et al. 2009 & 53 & 5.6 & Low SES & NRG & Reading control game & $6 \times 20 \min$ & $\begin{array}{c}\text { Symbolic comparison } \\
\text { Nonsymbolic } \\
\text { comparison }\end{array}$ & $\begin{array}{l}\mathrm{NRG}>\text { Reading on } \\
\text { symbolic comparison }\end{array}$ \\
\hline
\end{tabular}




\begin{tabular}{|c|c|c|c|c|c|c|c|c|}
\hline & & & & & & & Addition & $\begin{array}{l}\text { No improvements in } \\
\text { nonsymbolic } \\
\text { comparison. }\end{array}$ \\
\hline Räsanen et al. 2009 & 59 & 6.6 & $\begin{array}{l}\text { SEN-children, } \\
\text { TD }\end{array}$ & $\begin{array}{l}\text { NRG, Graphogame } \\
\text { Math }\end{array}$ & No game & $15 \times 10-15 \mathrm{~min}$ & $\begin{array}{c}\text { Symbolic comparison } \\
\text { Addition }\end{array}$ & $\begin{array}{c}\text { Interventions improved } \\
\text { symbolic comparison } \\
\text { No other effects }\end{array}$ \\
\hline $\begin{array}{l}\text { Obersteiner et al. } \\
2013\end{array}$ & 147 & 6.9 & $\mathrm{TD}$ & $\begin{array}{c}\text { NRG - Exact } \\
\text { NRG - Approximate } \\
\text { NRG Exact }+ \\
\text { Approximate }\end{array}$ & Language game & $10 \times 30 \mathrm{~min}$ & $\begin{array}{c}\text { Symbolic comparison } \\
\text { Nonsymbolic } \\
\text { comparison } \\
\\
\text { Approximate } \\
\text { calculation } \\
\text { Arithmetic }\end{array}$ & $\begin{array}{c}\text { NRG }>\text { Language game } \\
\text { Approximate NRG } \\
\text { showed largest effects } \\
\text { on comparison tasks }\end{array}$ \\
\hline Vilette et al. 2010 & 20 & 11.0 & $\mathrm{DD}, \mathrm{TD}$ & The Estimator & $\begin{array}{l}\text { Numerical games } \\
\text { without estimation }\end{array}$ & $5 \times 20 \min$ & $\begin{array}{l}\text { Standardized number } \\
\text { battery (ZAREKI) } \\
\text { Addition, subtraction }\end{array}$ & $\begin{array}{l}\text { The Estimator }> \\
\text { numerical games }\end{array}$ \\
\hline Kucian et al. 2011 & 32 & 9.5 & DD, TD & Rescue calcularis & & $25 \times 15 \mathrm{~min}$ & $\begin{array}{l}\text { Standardized number } \\
\text { battery (ZAREKI) }\end{array}$ & Both groups improved \\
\hline
\end{tabular}

Note. Only studies that included numerical magnitude comparison tasks or mathematics achievement tests as outcome measures were included and only these outcome measures were reported in the table. $\mathrm{BG}=$ Board Game. NRG $=$ Number Race Game. DD = Developmental Dyscalculia. $\mathrm{TD}=$ Typically Developing children. SEN $=$ Special Educational Needs. 


\section{BOXES}

\section{BOX 1: Magnitude Comparison Tasks}

The nature of numerical representations is typically explored using magnitude comparison tasks. In a standard nonsymbolic magnitude comparison task, participants are shown two dot arrays - or sequences of sounds - and asked to select the more numerous. The difficulty of making this decision is manipulated by varying the ratio or the numerical distance between the two arrays. For example, it is more difficult to distinguish 12 and 9 dots (ratio 0.75; numerical distance 3) than it is to distinguish 12 and 6 dots (ratio 0.5 ; numerical distance 6). Typical measures of performance include overall accuracy, response time (RT), ratio or distance effects or the $w$ index. This Weber fraction $(w)$ can be calculated on the basis of the participants' performance across different ratios, and provides a measure of the acuity of ANS representations. Individuals with a smaller $w$ have more precise ANS representations than those with a larger $w$.

To increase the possibility that participants use the number of dots rather than visual characteristics of the displays (e.g., dot size, density, total area), the dot arrays are typically constructed in such a manner so that these characteristics do not correlate with numerosity across the task, i.e. dot size, density and area vary across the experiment. However, recent data by Gebuis \& Reynvoet (2012) indicate that it is impossible to perfectly control for these non-numerical parameters and that the number of items in a set cannot be extracted independently of visual cues. While the existing studies all controlled for non-numerical parameters in their experimental design, the degree to which some visual properties of the stimuli are controlled for varies between them and this might also account for the differences in the results they obtained. In other words, it is unclear how participants use the various nonnumerical visual characteristics of the stimuli to guide their decision as to which array of dots 
is larger and how this process might differ between children who have various levels of mathematical competence. On the other hand, the data by Gebuis \& Reynvoet (2012) also call into question the degree to which non-symbolic number processing can truly be measured. Symbolic comparison tasks typically have the same format, except that the quantities are represented as Arabic digits, or in some studies, number words. Similar effects of distance or ratio on performance are observed when people perform this task. 


\section{BOX 2: The nature of symbolic representations}

For several authors (see Carey, 2004; 2009; Noël et al., 2008; Wiese, 2003, 2007), symbolic numbers do not acquire their meaning from a mapping with the ANS. Indeed recent research with adults suggests that the association between numerical symbols and the ANS may be much weaker than has been traditionally assumed (Lyons et al., 2012). Rather, learning the meaning of number words leads to the emergence of a new numerical representation that would be exact and with a semantic content based on the ordinal information enclosed in the symbol sequence. This exact representation would then connect with the ANS and this mapping would contribute to the increase of the precision of the ANS (Piazza et al. 2010; Piazza et al., in press). 


\section{BOX 3: Interventions that foster numerical magnitude processing}

\section{Number board games}

These games are similar to existing board games, such as snakes and ladders or chutes and ladders, and consist of consecutively numbered spaces, on which children have to move their token, depending on the number they produced via a spinner or dice. The games can differ in the spatial organisation of the numbered spaces (linear or circular). It is argued that these games provide multimodal cues to connections between symbols and their respective quantities: the larger the number indicating how many squares their token needs to be moved, the larger the distance the child needs to move the counter, the larger the number of moves to be made and the number of number words to be spoken (Siegler, 2009).

\section{Number Race Game}

The Number Race Game (Wilson et al., 2006) was specifically designed as a remediation program for children with DD. The game provides training in comparing numbers and tries to establish links between numbers and space by asking children to position their counter on a board, depending on the number of coins they earned during the comparison of two presented numbers. Numbers are presented in nonsymbolic and symbolic formats. At higher levels, small addition and subtraction problems are also included. The game is adaptive and presents stimuli depending on the level of the learner.

\section{The Estimator}

Estimator is a computer game for children with DD that aims to develop the connection between exact and approximate number representations in addition and subtractions (Vilette et al., 2010). A calculation problem $(12+23=)$ appears on the screen and children have to indicate the approximate position of the answer on a 0-100 number line. If this approximation is correct, the result of the calculation is presented and the next trial starts. If the estimate is 
incorrect, the number corresponding to the position of the cursor on the number line appears and the child is invited to estimate again.

Rescue Calcularis

In this game, children control a spaceship to rescue the planet "Calcularis" (Kucian et al., 2011), by travelling through 10 planets through which the child can refuel the spaceship to arrive at Calcularis. On each planet, children have to solve a series of problems of increasing difficulty: they have to position their spaceship on a number line, depending on the Arabic digit, collection of dots or arithmetic problem displayed on the spaceship. 


\section{BOX 4: Outstanding questions}

- How does the association between numerical magnitude processing and mathematics achievement change over developmental time? Is there a sensitive period for this association which should be the target of education?

- How do numerical symbols acquire developmentally their semantic meaning and how might this process be disrupted in children with DD?

- What is the role of non-numerical parameters (such as density of the arrays, the areas of individual dots, their luminance etc.) that covary with non-symbolic numerical magnitude stimuli in the typical and atypical development of the ANS?

- Are there cultural differences in the development of numerical magnitude representations?

- What are the effects of numerical magnitude interventions on children (with DD)'s numerical magnitude skills? Do these effects generalize to other mathematical skills (e.g., arithmetic, complex calculation, etc.) ? Do these effects sustain over longer time periods?

- How do brain structure and function change in response to numerical magnitude interventions? 